\title{
MAIC-COBIT: método interativo entre inteligência competitiva e governança de Tecnologia da Informaçã̃o
} MAIC-COBIT: interactive model between competitive
intelligence and information technology governance MAIC-COBIT: método interactivo entre inteligencia
competitiva y gobernanza de Tecnología de la Información

\author{
Fernando Celso de Campos \\ Doutorado em Engenharia Mecânica \\ Professor titular da Universidade Metodista de Piracicaba
}

Anderson EvandRo do Prado

Mestre em Engenharia de Produção

Universidade Metodista de Piracicaba

REsumo As organizações necessitam sempre estar atentas em relação ao ambiente competitivo, buscando atualizações e inovações para não serem surpreendidas pelos diversos fatos que podem influenciar seu negócio, direta ou indiretamente. A procura por técnicas que possam auxiliar as organizações são cada vez maiores e a Inteligência Competitiva (IC) é uma delas, obtendo e gerenciando informações úteis para fins econômicos e de negócios. Na literatura, identificaram-se 22 ciclos de inteligência competitiva possíveis e notou-se que não existe neles qualquer alinhamento a uma norma em geral nem a uma norma de governança, com a finalidade de padronizar e avaliar o processo do ciclo de IC.

O objetivo deste artigo é apresentar um método de avaliação do ambiente de IC, com base em uma norma de governança de TI, o CobiT v4.1. Esse método ficou denominado de MAIC_ CobiT. A abordagem metodológica para gerar o MAIC-CobiT passou pela etapa de revisão bibliográfica, identificando-se os ciclos de inteligência competitiva existentes, dos quais foi selecionado um deles, que serviu de base para a elaboração da proposta do método, bem como, alguns aspectos pré-selecionados da norma CobiT v4.1 e, posteriormente, foi feita uma etapa de verificação de sua aplicabilidade por meio de um questionário junto a sete Especialistas/ profissionais e oito Acadêmicos previamente selecionados. Por intermédio do MAIC_CobiT, pretende-se garantir que o ambiente de IC passe a ser avaliado regularmente e ao longo do tempo se torne mais estável além do que a organização possa obter maior vantagem competitiva em relação aos seus concorrentes, pela aplicação dos planos de ação prescritos.

Palavras-chave: Inteligência Competitiva. Cobít. Método de Avaliação e Vantagem Competitiva. 
Aвstract Organizations always need to be vigilant in relation to the competitive environment, seeking updates and innovations so as not to be surprised by the various facts that may influence your business, either directly or indirectly. The search for techniques that can help organizations are getting bigger and the competitive intelligence $(\mathrm{CI})$ is one of them, obtaining and managing information useful for economic and business purposes. In the literature, identified 22 competitive intelligence cycles possible and noted that there is in them any alignment to a standard in General nor a standard of governance, in order to standardize and evaluate the process of CI. The purpose of this article is to present a method of IC environment assessment, based on a standard of information technology governance, CobiT $4.1 \mathrm{v}$. This method was called MAIC_CobiT. The methodological approach to generate the MAIC-CobiT crossed leg of literature review identifying competitive intelligence cycles exist, of which was selected one of them that formed the basis for the elaboration of the proposal of the method as well as some pre-selected aspects of standard CobiT $4.1 \mathrm{v}$, and later was made a step of verification of your application by means of a questionnaire with 7 Professionals and 8 Scholars previously selected. Through MAIC_CobiT, we intend to ensure that the IC environment will be evaluated regularly and over time become more stable than what the organization can achieve greater competitive advantage relative to its competitors, for the implementation of the plans prescribed action.

Keywords: Competitive intelligence. CobiT. Method of evaluation and competitive AdVANTAGE.

RESUMEN Las organizaciones necesitan siempre estar atentas en relación al ambiente competitivo, buscando actualizaciones e innovaciones para no ser sorprendidas por los diversos hechos que pueden influenciar su negocio, directa o indirectamente. La búsqueda de técnicas que pueden ayudar a las organizaciones es cada vez mayor y la Inteligencia Competitiva (IC) es una de ellas, obteniendo y administrando informaciones útiles para fines económicos y de negocios. En la literatura se identificaron 22 ciclos de inteligencia competitiva posibles y se notó que no existe en ellos ninguna alineación a una norma en general y ni a una norma de gobernanza, con la finalidad de estandarizar y evaluar el proceso del ciclo de IC.

El objetivo de este artículo es presentar un método de evaluación del ambiente de IC, basado en una norma de gobernanza de TI, el CobiT v4.1. Este método se denominó MAIC_CobiT. El enfoque metodológico para generar el MAIC-CobiT pasó por la etapa de revisión bibliográfica identificándose los ciclos de inteligencia competitiva existentes, de los cuales fue seleccionado uno de ellos que sirvió de base para la elaboración de la propuesta del método así como algunos aspectos preseleccionados de la norma CobiT v4.1 y posteriormente se realizó una etapa de verificación de su aplicabilidad por medio de un cuestionario junto a 7 Especialistas / profesionales y 8 Académicos previamente seleccionados. Por medio del MAIC_CobiT, se pretende garantizar que el ambiente de IC pase a ser evaluado regularmente ya lo largo del tiempo se haga más estable además de que la organización pueda obtener mayor ventaja competitiva en relación a sus competidores, por la aplicación de los planes de gestión acción prescritos.

Palabras clave: Inteligencia Competitiva. CobíT. Método de Evaluación y Ventaja Competitiva. 


\section{INTRODUÇÃO}

A informação hoje, com o advento da computação em nuvem, big data, redes sociais, banda larga, entre outros, não é mais problema em termos de volume, variedade, velocidade, veracidade e valor. Com esse aumento das informações, facilidade de acesso a elas, e o desafio de processá-las em tempo hábil para tomada de decisão, surgiu a necessidade de tecnologias e ferramentas de gestão de informação (TI). Tais tecnologias, ferramentas, serviços e soluções tecnológicas cada vez são mais eficientes e inovadores, em busca de vantagem competitiva.

Nem sempre a área de TI é compreendida como uma área estratégica, o que a torna reativa, não atendendo a sua função, que é auxiliar na tomada de decisão em busca de vantagem competitiva, de um modo mais preventivo e proativo. Entre os diversos fatos que podem levar a TI a ser reativa, pode-se destacar a não adoção de princípios de governança.

Com a finalidade de auxiliar as organizações a controlar sua TI, tornando-a proativa, existem as normas de governança de TI, por meio de padrões, técnicas, avaliações, indicadores e leis de compliance (Sarbanes-Oxley, Basel II, HIPAA, entre outros). Governança de TI é um conjunto de ações/diretrizes/padrões que envolvem a responsabilidade dos executivos, do conselho de administração, dos profissionais de TI de empresa. Ou seja, consiste na liderança, estruturas organizacionais e processos que garantam à empresa que a área de TI entenda as estratégias e objetivos da empresa (MARNEWICKA \& LABUSCHAGNEB, 2011).

Alguns exemplos de normas de Governança de TI são: Information Technology Infrastructure Library (ITIL), Control Objectives for Information and related Technology Control Objectives for Information and related Technology (CobiT), Capability Maturity Model Integration (CMMI), IT Governance Maturity Model, entre outros (CAMPOS \& SANTOS, 2012).

Se as empresas podem medir com sucesso a sua TI, tal medição pode ajudar a garantir seus investimentos e processos, e assim contribuir positivamente para o desempenho geral da organização (ALI; GREEN \& ROBB, 2015). A importância da governança tanto para os investimentos em TI como para as melhorias dos processos, vem ganhando cada vez mais atenção no mundo dos negócios.

O mundo está passando por grandes transformações econômicas, políticas, tecnológicas que influenciam todos os níveis sociais (GOMES \& BRAGA, 2004), nesse contexto as organizações se defrontam com a rapidez das mudanças, que vêm associadas a uma crescente competição mundial. Para acompanhar tais mudanças, é preciso estar atualizado com as informações que são geradas diariamente, com o objetivo de prever a situação do cenário competitivo futuro no curto, médio, e longo prazo.

No entanto, mediante esse cenário e essa imensa quantidade de informações, surgem alguns questionamentos e direcionamentos, que podem levar à geração de vantagem competitiva, que é uma disciplina de Inteligência, no caso Inteligência de Mercado (IM) ou Inteligência Competitiva (IC).

IC pode ser compreendida como uma ferramenta administrativa para identificar oportunidades e neutralizar as ameaças do mercado, ou seja, um processo ético de identificação, coleta, tratamento, análise e disseminação da informação estratégica para a organização, viabilizando seu uso no processo decisório (GOMES \& BRAGA, 2004). 
Conforme destacado por Pellissier \& Nenzhelele (2013), os processos de IC são descritos como um ciclo, ou seja, um processo sistematizado e contínuo, em que, ao final de cada etapa, se inicia a outra, sendo assim descritos por alguns autores como modelos de IC ou Ciclos de Inteligência.

A Society of Competitive Intelligence Professionals (SCIP) é uma organização mundial, sem fins lucrativos, para profissionais de IC, que tem desenvolvido um debate, envidando esforços e apontando como tendência que a IC não tem sido tratada formalmente pelas organizações. Corroborando isso, estão os trabalhos de Swartz (2005) e de Sewdass \& Du Toit (2014). Conforme analisou Swartz (2005) à época, 100 das maiores empresas dos EUA utilizavam IC para seus processos decisórios. Essa utilização era de forma inadequada, porque não ocorria de maneira sistematizada. Outro estudo realizado por Sewdass \& Du Toit (2014) também revelou que na África do Sul poucas organizações usam IC de maneira formal sistemática, e não existe um departamento específico para desenvolvimento de inteligência, ou um profissional especialista no assunto que desenvolva tal vantagem competitiva por meio da IC.

Ambas as pesquisas (SWARTZ, 2005; SEWDASS \& DU TOIT, 2014) demonstram a incipiência e o grau de importância ainda restrito da IC na prática quotidiana das empresas, apesar de reconhecerem a importância dela para os negócios, e destacam que existe uma resistência por parte das empresas.

No Brasil, existe a Associação Brasileira dos Analistas de Inteligência Competitiva (ABRAIC), que é responsável por regulamentar as atividades de IC, por meio dela se destacam os mesmos fatores e as mesmas tendências já mencionadas. Ou seja, no Brasil a IC vem apresentando resultados semelhantes às pesquisas desenvolvidas pelos autores já citados, por exemplo, Rodrigues et al. (2011) demonstram que a maturidade no uso de IC nas empresas brasileiras está ainda em seus primeiros estágios, e apontaram algumas dificuldades a serem superadas para a adoção mais efetiva de ferramentas e/ou sistema de IC.

Ainda, esses mesmos autores mencionam que, apesar de as empresas conhecerem ou terem ouvido falar em IC não a aplicam de modo formal, ou seja, existe um responsável por monitorar as informações, porém tal informação nem sempre tem o efeito desejado ou não foi planejado corretamente o foco para sua coleta.

Alfredo Passos, em entrevista à revista Exame (2013), mencionou que o Brasil atingiu os primeiros 20 anos de IC e houve um crescimento das empresas que utilizam tais técnicas, pois das 1.000 empresas listadas por Melhores e Maiores (EXAME, 2013), certamente 800 empresas possuíam um profissional com alguma atividade ligada à área de IC, mas no âmbito tático, ou seja, ainda há poucas empresas pensando em tendências do mercado ou do setor, que é exatamente a raiz da função da IC.

Essas pesquisas (SWARTZ, 2005; SEWDASS \& DU TOIT, 2014; RODRIGUES et al., 2011) revelam que as empresas buscam a IC devido à alta competitividade, e tal busca ocorre independentemente do segmento e tamanho da empresa. Existe, também, uma resistência das organizações para implementar uma área dedicada à IC.

Portanto, tanto em âmbito nacional quanto internacional as empresas que operam no mercado estão estreitamente envolvidas na criação e gestão de informações úteis para fins econômi- 
cos e de negócios (FRANCO et al., 2011), logo os processos decisórios que utilizam como fontes a IC deveriam dar garantias que a governança de TI está sendo observada/cumprida.

Assim, fica posto o desafio de buscar um modo de garantir que a área de IC esteja seguindo uma norma de governança de TI em todos os momentos de seu processo, pois uma área de IC reativa é tão irrelevante quanto uma TI sem governança.

O objetivo deste artigo é apresentar um caminho de solução como o Método de Análise de Inteligência Competitiva ancorado em processos de gestão e governança do COBIT, intitulado MAIC-COBIT.

\section{INTELIGÊNCIA COMPETITIVA}

As últimas décadas testemunharam a emergente economia da inteligência (conhecimento), como importante área de pesquisa, tornando-se fundamental para os negócios (COZZARIN \& PERCIVAL, 2006; FELMAN et al., 2006; PERCIVAL \& COZZARIN, 2008; SEWDASS \& DU TOIT, 2014).

A informação está cada vez mais abundante nos meios digitais, cada vez mais fundamental entre as organizações, e a sua compreensão em tempo hábil traz consigo um processo de inovação ou geração de vantagem competitiva (CANONGIA et al., 2007).

Nesse sentido, a IC é uma ferramenta de apoio para as organizações se manterem no atual ambiente em que vivem de constantes mudanças. Ela reúne informações sobre os envolvidos e acerca de situações relevantes do cenário competitivo no qual a empresa atua, obtendo informações sobre concorrentes, clientes, fornecedores e tecnologias relevantes (DISHMAN; CALOF, 2008; ZHENG et al., 2013).

Cada vez mais as organizações estão buscando tais técnicas de IC, porque ela suporta as necessidades informacionais, obrigando-as a olhar para além de suas atividades internas e integrar eventos externos para entender melhor seu cenário competitivo (STRAUSS \& TOIT, 2010).

Existem vários modelos de IC ou ciclos de inteligência, no entanto, as empresas que aplicam/usam IC o estão fazendo de um modo desordenado e sem sistematização alguma (SWARTZ, 2005; SEWDASS \& DU TOIT, 2014; RODRIGUES et al., 2011). Ou seja, não há governança, logo, não possuem controle ou até mesmo padronização dos processos. O uso ordenado e sistematizado das técnicas de IC pode ser alcançado por meio de uma norma de governança de TI (CobiT), avaliando os processos do ciclo de inteligência de forma sistematizada.

Um fato importante é que as empresas brasileiras estão evoluídas no uso dos modelos de governança de TI, pois, por meio de uma pesquisa (ITSMF, 2015) realizada pelo ITSMF Brasil (IT Service Management Forum), com 200 empresas no país, ficou revelado que 85\% das companhias já usam algum framework, 16\% das corporações usam CobiT, e 11\% Balanced Scorecard (BSC). O PMBoK do Project Management Institute (PMI) e Capability Maturity Model Integration (CMMI) foram citados por 6\% dos entrevistados.

Outras empresas brasileiras como a Petrobrás, Banco Bradesco, Banco Itaú, Banco do Brasil e Vale, são classificadas no "Top 55" entre as maiores empresas do mundo, e a governança de TI tem sido promovida por essas empresas em seus relatórios institucionais como práticas implementadas de boa gestão de TI (LUNARDI et al., 2014). 
Os serviços de inteligência possuem raízes militares. O general Sun Tzu, em seus apontamentos sobre a Arte da Guerra, 2.500 anos antes de Cristo, já creditava ao serviço de inteligência a condição fundamental para um exército ser bem sucedido nas guerras. A visão desse general sobre uso inteligente e estratégico da informação permaneceu ao longo dos tempos como fundamento da inteligência militar (RODRIGUES et al., 2011).

O aperfeiçoamento das técnicas da IC atingiu seu ápice durante a Segunda Grande Guerra Mundial e, a seguir, durante o período da Guerra Fria, ou seja, a IC foi compreendida como um processo formal de práticas gerenciais, sendo incorporada pelas empresas (TYSON, 1998; RODRIGUES et al., 2011).

Portanto, IC é uma ferramenta administrativa para identificar oportunidades e neutralizar as ameaças do mercado. Dentro de uma organização, a IC pode ser utilizada por todos os setores. Conforme Amaral et al. (2008), a IC auxiliaria o marketing (para identificar novos produtos), auxiliaria a produção (para conhecer os custos produtivos), auxiliaria os recursos humanos (para contratar funcionários com características próximas à política da empresa).

Queyras e Quoniam (2006) descrevem que a IC é um processo de aprendizagem motivado pela competitividade e ancorado nas informações que podem ser fundamentais para a tomada de decisão e até mesmo desenvolvimentos da estratégia da empresa. Reúne informações sobre os envolvidos e sobre situações relevantes do cenário competitivo que atua, como informações sobre os concorrentes, clientes, fornecedores, e tecnologias relevantes (DISHMAN \& CALOF, 2008; ZHENG et al., 2013).

Tais informações podem ser consideradas como um fator estratégico para o aumento da competitividade da empresa, como observado por Choo (1998), qualquer mudança ou desenvolvimento no ambiente externo das organizações cria sinais que devem ser analisados com dedicação.

Ainda, Capuano et al. (2009) observam que esses sinais podem ser fracos (quando difíceis de serem detectados), confusos (difíceis de serem analisados) ou espúrios (quando não indicam mudanças verdadeiras).

Apesar de não ser uma tarefa de fácil execução, fica evidente que o ambiente externo sempre apresentará sinais de mudanças que devem ser acompanhadas para não ser surpreendido pela concorrência. A IC tem esse papel de auxiliar as organizações a monitorar esse ambiente.

Os conceitos de IC propostos por alguns autores são apresentados no Quadro 1. 


\begin{tabular}{|cl|}
\hline AUTOR & \multicolumn{1}{c|}{ DEFINIÇÃo } \\
& IC é um processo de monitoramento do meio ambiente competitivo com \\
& o objetivo de habilitar gerentes sênior, em empresas de todos os tama- \\
SCIP (2015) & nhos, a tomar decisões com base informacional sobre assuntos relativos a \\
& marketing, a pesquisa e desenvolvimento (P\&D) e a investimentos táticos \\
& para as estratégias de negócio de longo prazo. \\
& IC é um processo analítico de transformação de inteligência desagregada \\
& do concorrente em conhecimento estratégico relevante, preciso e utili- \\
FULD (1985) & zável sobre sua posição, desempenho, capacidades e intenções, ou seja, \\
& informação específica em tempo hábil. \\
& IC é um processo informacional proativo que conduz à melhor tomada \\
& de decisão, seja ela estratégica ou operacional, um processo sistemático \\
que visa descobrir as forças que regem os negócios, reduzir o risco e con- & duzir o tomador de decisão a agir antecipadamente, bem como, proteger \\
ABRAIC (2015) & o conhecimento gerado. \\
& IC é um processo ético de identificação, coleta, tratamento, análise e dis- \\
& seminação da informação estratégica para a organização, viabilizando seu \\
uso no processo decisório.
\end{tabular}

Quadro 1: Conceitos e Definições IC.

Fonte: elaborado pelos autores.

Ou seja, as atividades de IC possuem a finalidade de compreender e saber como se portar frente ao ambiente de negócios e utilizar essas informações para atingir os objetivos da empresa, por meio da identificação de tendências nas quais a organização atua (FLEISHER et al., 2008; KAHANER, 1996; KAHANER, 1997).

A detecção precoce de mudanças ambientais pode ser compreendida como uma vantagem competitiva, pois permite que as empresas possam responder com contramedidas adequadas. Afinal, é necessário tempo para se adaptar a mudanças de ambiente. Assim, as empresas devem ter a capacidade de antecipar as mudanças e imaginar as consequências de respostas alternativas a essas mudanças. Portanto, a IC serve como uma ferramenta estratégica para facilitar a identificação de potenciais oportunidades e ameaças (SEWDASS \& DU TOIT, 2014). Desse modo, a IC capacita as empresas, independentemente de seu porte, a monitorar seu desenvolvimento e os passos dos concorrentes dispondo aos tomadores de decisões dados e informações significativas para apoio à decisão. A IC agrega valor à empresa, pois desenvolve mecanismos que possibilitam conhecer as iniciativas e tendências da concorrência, que podem afetar a organização no mercado (RODRIGUEZ \& FONTANA, 2005). Tais mecanismos devem ser capazes de identificar, analisar e responder com eficácia as mudanças no ambiente no qual competem e muitas organizações utilizam a IC como seu maior aliado para continuar competindo. 
As empresas brasileiras devem se adaptar aos cenários e às suas mudanças, envolvendo-se nos processos de transformações e mudanças, sejam elas econômicas, políticas e tecnológicas. Precisam estar alinhadas com as melhores práticas competitivas (RODRIGUES et al., 2012). Estudo realizado por Sewdass \& Du Toit (2014) revelou que poucas organizações utilizam IC de maneira formal sistemática. Em outro estudo, Rodrigues et al. (2011) destacam que 74\% das empresas brasileiras possuem IC, informalmente, existe um profissional que atua na área de análise das informações dos concorrentes, porém não há uma equipe preparada e dedicada somente para esse fim.

Alguns comportamentos de IC se referem acerca de como pessoas ou organizações coletam, organizam e utilizam essas informações (KAHANER, 1997). Segundo Starec, Gomes \& Bezerra (2006), o principal aspecto da IC é buscar com simplicidade, valorizando mais os resultados do que a infraestrutura, assim sendo, a ênfase da busca é voltada para informações que possuem valor ao processo de tomada de decisões.

A busca por tais informações deve ser realizada com cuidado pelos profissionais da área de IC, pois esta deve ser feita da forma mais ética e transparente possível. Tanto para o SCIP, quanto para a ABRAIC, a ética é muito importante para quem atua nessa área, por isso essas associações disponibilizam um código de ética para profissionais de IC (SCIP, 2015; ABRAIC, 2015). Toda organização, ao definir seus padrões de ética, deverá estar preparada para responder futuras críticas que possam ocorrer relacionadas ao modo como obtiveram as informações (GOMES \& BRAGA, 2004). Os gestores envolvidos no sistema de IC devem ser especialistas no assunto para desenvolver o melhor produto de inteligência, favorecendo assim uma tomada de decisão mais precisa. A construção da IC em organizações é um processo cultural. Deve ser construída passo a passo, em uma organização onde a IC se torna o fundamento do negócio, exigindo assim uma equipe especializada, organizada, e coordenada para apoiar os tomadores de decisão com informações adequadas (PRESCOT'T, 2002; GOMES \& BRAGA, 2004; PELLISSIER \& NENZHELELE, 2013). Portanto, existe uma exigência por esses processos de IC, e essas exigências são motivadas pela geração de vantagem competitiva por meio da manipulação e disponibilidade dos dados ricos em informações sobre os concorrentes, que, às vezes, são difíceis de adquirir ou simplesmente não estão sendo monitoradas pelas empresas. Para mapear os modelos de IC existentes, foi realizada uma bibliometria de 1990 a 2014, chegando-se a 22 modelos (Quadro 2). Principal evidência: consenso das principais etapas do ciclo de IC, de coleta à divulgação das informações. 


\begin{tabular}{|c|c|c|c|c|c|c|c|c|c|c|c|}
\hline & \multicolumn{11}{|c|}{ FASES DOS CICLOS DE INTELIGÊNCIA COMPETITIVA IDENTIFICADOS PELA PESQUISA } \\
\hline $\begin{array}{l}\text { AUTOR } \\
\text { (ANO) }\end{array}$ & $\begin{array}{c}\text { Coleta de } \\
\text { informaçōes }\end{array}$ & \begin{tabular}{|c} 
Fases de \\
divulgação \\
das \\
informaçōes
\end{tabular} & $\begin{array}{l}\text { Análise das } \\
\text { informaçōes }\end{array}$ & $\begin{array}{c}\text { Planejamento e } \\
\text { direşāo }\end{array}$ & $\begin{array}{c}\text { Estabelecer as } \\
\text { necessidades de } \\
\text { IC }\end{array}$ & $\begin{array}{c}\text { Processo e } \\
\text { estrutura }\end{array}$ & $\begin{array}{c}\text { Consciência e } \\
\text { cultura } \\
\text { organizacional }\end{array}$ & Feedhack & $\begin{array}{l}\text { Processsamento de } \\
\text { informaçāo }\end{array}$ & $\begin{array}{l}\text { Desenvolvimento } \\
\text { de competências }\end{array}$ & Açāo \\
\hline Calof (1998) & $\checkmark$ & $\checkmark$ & $\checkmark$ & $\checkmark$ & $\checkmark$ & & & & & & \\
\hline $\begin{array}{l}\text { Calof e } \\
\text { Skinner } \\
(1998)\end{array}$ & $\checkmark$ & $\checkmark$ & $\checkmark$ & $\checkmark$ & & & & & & & \\
\hline $\begin{array}{c}\text { Kahaner } \\
(1998)\end{array}$ & $\checkmark$ & $\checkmark$ & $\checkmark$ & $\checkmark$ & & & & & & & \\
\hline $\begin{array}{c}\text { Rouach e } \\
\text { Santi (2001) }\end{array}$ & $\checkmark$ & $\checkmark$ & & & $\checkmark$ & $\checkmark$ & $\checkmark$ & & & & \\
\hline $\begin{array}{l}\text { Cruywagen } \\
\text { (2002) }\end{array}$ & $\checkmark$ & $\checkmark$ & $\checkmark$ & $\checkmark$ & & & & & & & \\
\hline $\begin{array}{l}\text { Dishman e } \\
\text { Calof (2002) }\end{array}$ & $\checkmark$ & $\checkmark$ & $\checkmark$ & $\checkmark$ & & $\checkmark$ & $\checkmark$ & & & & \\
\hline $\begin{array}{l}\text { Muller } \\
\text { (2002) }\end{array}$ & $\checkmark$ & $\checkmark$ & $\checkmark$ & $\checkmark$ & & $\checkmark$ & $\checkmark$ & & & & \\
\hline $\begin{array}{c}\text { Viviers, } \\
\text { Saayman e } \\
\text { Muller } \\
(\mathbf{2 0 0 5 )}\end{array}$ & $\checkmark$ & $\checkmark$ & $\checkmark$ & $\checkmark$ & & $\checkmark$ & $\checkmark$ & & & & \\
\hline $\begin{array}{l}\text { Wright e } \\
\text { Calof (2006) }\end{array}$ & $\checkmark$ & $\checkmark$ & $\checkmark$ & $\checkmark$ & & & & & & & \\
\hline $\begin{array}{c}\text { Botha e Boon } \\
\text { (2008) }\end{array}$ & $\checkmark$ & $\checkmark$ & $\checkmark$ & $\checkmark$ & $\checkmark$ & & & $\checkmark$ & & $\checkmark$ & \\
\hline Bose (2008) & $\checkmark$ & $\checkmark$ & $\checkmark$ & $\checkmark$ & & & & $\checkmark$ & & & \\
\hline $\begin{array}{c}\text { Sawka e } \\
\text { Hohhof } \\
\text { (2008) }\end{array}$ & $\checkmark$ & $\checkmark$ & $\checkmark$ & $\checkmark$ & & & & & & & \\
\hline Cucui (2009) & $\checkmark$ & $\checkmark$ & $\checkmark$ & & $\checkmark$ & & & & & & \\
\hline $\begin{array}{l}\text { Shi, Mou e } \\
\text { Wan (2009) }\end{array}$ & $\checkmark$ & $\checkmark$ & & $\checkmark$ & & & & & $\checkmark$ & & \\
\hline $\begin{array}{c}\text { Haddadi, } \\
\text { Dousset e } \\
\text { Berrada } \\
\text { (2010) }\end{array}$ & $\checkmark$ & $\checkmark$ & & & $\checkmark$ & & & & $\checkmark$ & & \\
\hline $\begin{array}{c}\text { Strauss e Du } \\
\text { Toit (2010) }\end{array}$ & $\checkmark$ & $\checkmark$ & $\checkmark$ & $\checkmark$ & & $\checkmark$ & $\checkmark$ & & & $\checkmark$ & \\
\hline $\begin{array}{l}\text { McGonagle e } \\
\text { Vella (2012) }\end{array}$ & $\checkmark$ & $\checkmark$ & & & $\checkmark$ & & & $\checkmark$ & $\checkmark$ & & v \\
\hline $\begin{array}{c}\text { Pellissier e } \\
\text { Nenzhelele } \\
\text { (2013) }\end{array}$ & $\checkmark$ & $\checkmark$ & $\checkmark$ & $\checkmark$ & & & & $\checkmark$ & & & \\
\hline $\operatorname{SCIP}(2015)$ & $\checkmark$ & $\checkmark$ & $\checkmark$ & $\checkmark$ & & & & $\checkmark$ & & & \\
\hline $\begin{array}{c}\text { Gomes \& } \\
\text { Braga (2004) }\end{array}$ & $\checkmark$ & $\checkmark$ & $\checkmark$ & $\checkmark$ & & & & $\checkmark$ & & & \\
\hline $\begin{array}{c}\text { Melo e } \\
\text { Medeiros } \\
\text { (2007) }\end{array}$ & $\checkmark$ & $\checkmark$ & $\checkmark$ & $\checkmark$ & & $\checkmark$ & & & & & \\
\hline Motte (2007) & $\checkmark$ & $\checkmark$ & $\checkmark$ & $\checkmark$ & & & $\checkmark$ & & & & \\
\hline
\end{tabular}

Quadro 2: Etapas Ciclos de IC Análise Bibliométrica.Fonte: Elaborado pelos autores. 


\section{Modelo de Gomes \& Braga (2004)}

Geralmente, ciclos de IC envolvem cinco etapas: i) Identificação das Necessidades de Informação; ii) Coleta; iii) Análise da Informação; iv) Disseminação e v) Avaliação. Para que a IC cumpra suas funções, é necessária uma abordagem estruturada das etapas já citadas. Cada uma das etapas é representada conforme a Figura 1.

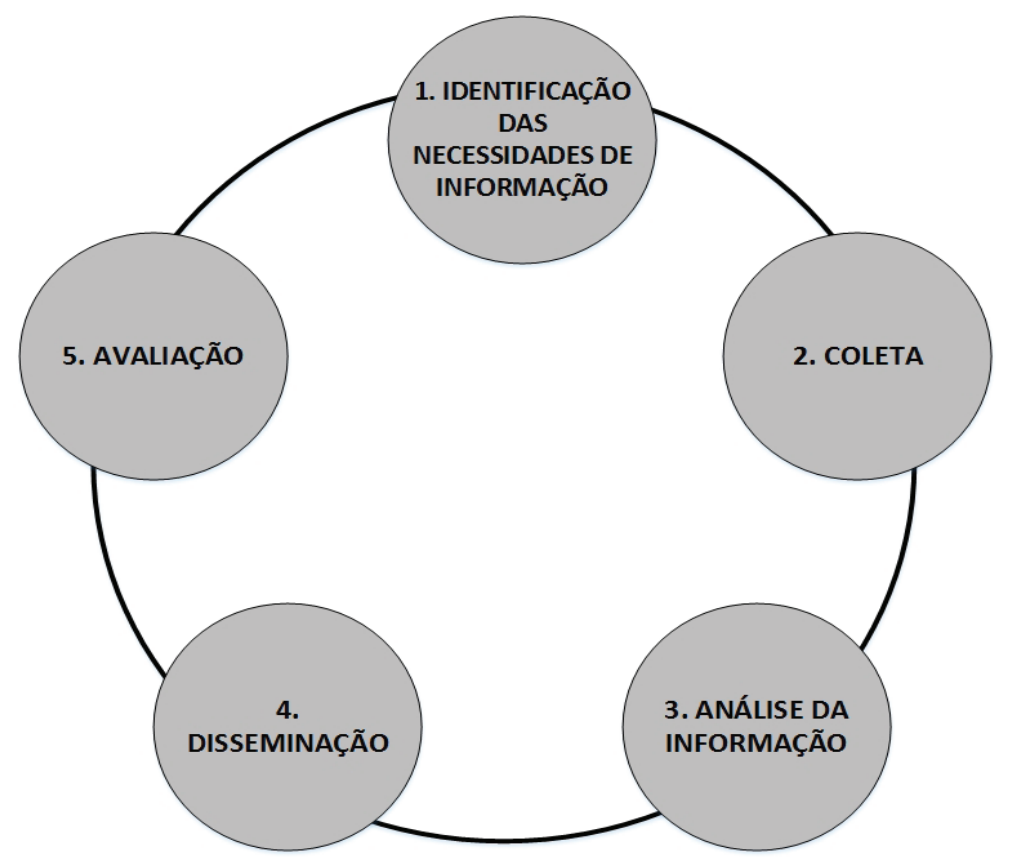

Figura 1: Etapas do Ciclo de IC de Gomes \& Braga (2004).

Fonte: Adapt. Gomes e Braga (2004).

Na primeira etapa (Identificação das Necessidades de Informação), é preciso planejar, identificando qual é a necessidade da informação que se precisa, quais bases de conhecimento serão utilizadas, qual tipo de coleta será necessário e coordenar, definir o objetivo, e a linha de pesquisa (GOMES; BRAGA, 2004).

Questões a serem respondidas na etapa de planejamento a partir de Porter (1996):

i) O que vem dirigindo a concorrência em minha indústria ou nas indústrias nas quais estou pensando entrar?

ii) Quais atitudes os concorrentes, provavelmente, assumirão e qual a melhor maneira de responder?

iii) De que modo minha indústria irá se desenvolver?

Iv) Qual a melhor posição a ser adotada pela empresa para competir a longo prazo?

$\mathrm{Na}$ segunda etapa (Coleta), serão realizadas as atividades de identificação e classificação das fontes de informação, coleta e tratamento. Gomes \& Braga (2004) descrevem que, a partir da necessidade de informação e das vigilâncias identificadas na etapa 1, deve-se planejar uma 
ação desenhando a melhor estratégia, identificando a fonte que seria usada e definindo se é preciso contratar uma organização especializada ou se o serviço será realizado por membros da organização.

A terceira etapa (Análise da Informação), que é a análise das informações, também poderia ser denominada como "gerador de inteligência", pois nessa etapa o analista transforma informações coletadas em uma avaliação significativa, completa e confiável. Importante destacar que a análise deverá ser feita por um profissional chave que tenha conhecimento sobre as necessidades de informação da empresa e que esteja diretamente ligado à alta direção.

Na quarta etapa (Disseminação), a disseminação envolve a entrega da informação analisada, ou seja, é o produto da IC. A palavra-chave dessa etapa é o convencimento. Conforme Gomes \& Braga (2004), existem duas formas de disseminação: focada e geral.

Disseminação focada: ocorre quando determinado usuário solicita um tipo de informação específica e a Disseminação geral: ocorre quando a inteligência é disseminada por toda a empresa.

De acordo com Gomes \& Braga (2004), a quinta etapa (Avaliação) é uma das mais importantes do processo de IC, pois nela devem ser avaliados dois aspectos: o primeiro diz respeito ao desempenho de cada uma das fases que compõem o sistema e o segundo aspecto é a avaliação junto aos usuários dos resultados do sistema.

Por meio desses conceitos, pode-se verificar qual foi a eficácia da IC, se ele atingiu a expectativas, dessa forma pode-se encontrar erros e/ou falhas e assim aprender com os mesmos evitando que ocorram novamente.

\section{COBIT VERSÃO 4.1}

Para o tratamento e controle dos processos envolvidos na IC, utilizou-se o CobiT v.4.1 que, por meio de seus grupos e processos, pode auxiliar nas etapas do ciclo de IC.

O CobiT vem como uma ferramenta facilitadora para as empresas, por intermédio de um guia de boas práticas, demonstrando o que deve ser medido para que a TI agregue valor à empresa, por meio da governança. Desenvolvido na década de 1990 pela ISACA (Information System Audit and Control Association), tem por objetivo fornecer orientações de boas práticas por intermédio de um modelo de domínios e processos apresentando atividades em uma estrutura lógica e gerenciável (ISACA, 2015). Uma característica importante sobre o COBIT é que ela é independente da plataforma de TI adotada pela organização, afinal seu uso é voltado para o negócio (WEILL, 2004).

Essas orientações consistem em alinhar os objetivos de TI aos objetivos de negócios, provendo métricas e modelos de maturidade para medir a sua eficácia e identificando as responsabilidades relacionadas aos processos do negócios e da TI (ISACA, 2014). Por se tratar de orientações, o CobiT possui uma ampla área de aplicação não somente TI. O CobiT suporta a governança de TI provendo uma metodologia que visa assegurar as principais áreas de foco: que a área de TI esteja alinhada com os negócios; que a área de TI habilite o negócio e maxi- 
mize os benefícios; que os recursos de TI sejam usados responsavelmente; que os riscos de TI sejam gerenciados apropriadamente.

O CobiT é voltado para três níveis organizacionais distintos na organização: gerentes, usuários e auditores. Os gerentes necessitam realizar avaliações dos riscos e o controle dos investimentos em TI; os usuários, precisam garantir a qualidade dos serviços que são prestados para os clientes internos e externos; e no último nível, os auditores têm a necessidade de avaliar o trabalho de gestão de TI e também de aconselhar o controle interno da organização (ISACA, 2014).

Portanto, para que o objetivo final seja alcançado, é preciso planejar adequadamente, considerando todas as variáveis existentes e ainda planejando o que fazer com aquelas que não eram previstas (BALLONI, 2014).

O CobiT se baseia no princípio de que os recursos de TI devem ser gerenciados por um conjunto sistemático de processos agrupados para fornecer informações que sustentem as estratégias corporativas. Para atender a esses requisitos, o CobiT especifica 34 processos de segurança (atividades e riscos) que devem ser gerenciados para a governança de TI eficaz (ISACA, 2014).

Os processos de TI estão organizados em quatro domínios (Figura 2), que correspondem às principais áreas de responsabilidade dentro da TI: Planejar e Organizar (PO) - Provê direção para entrega de soluções (AI) e entrega de serviços (DS); Adquirir e Implementar (AI) - Provê as soluções e as transfere para se tornarem serviços; Entregar e Suportar (DS) Recebe as soluções e as torna passíveis de uso pelos usuários finais; Monitorar e Avaliar (ME) - Monitora todos os processos para garantir que a direção definida seja seguida.

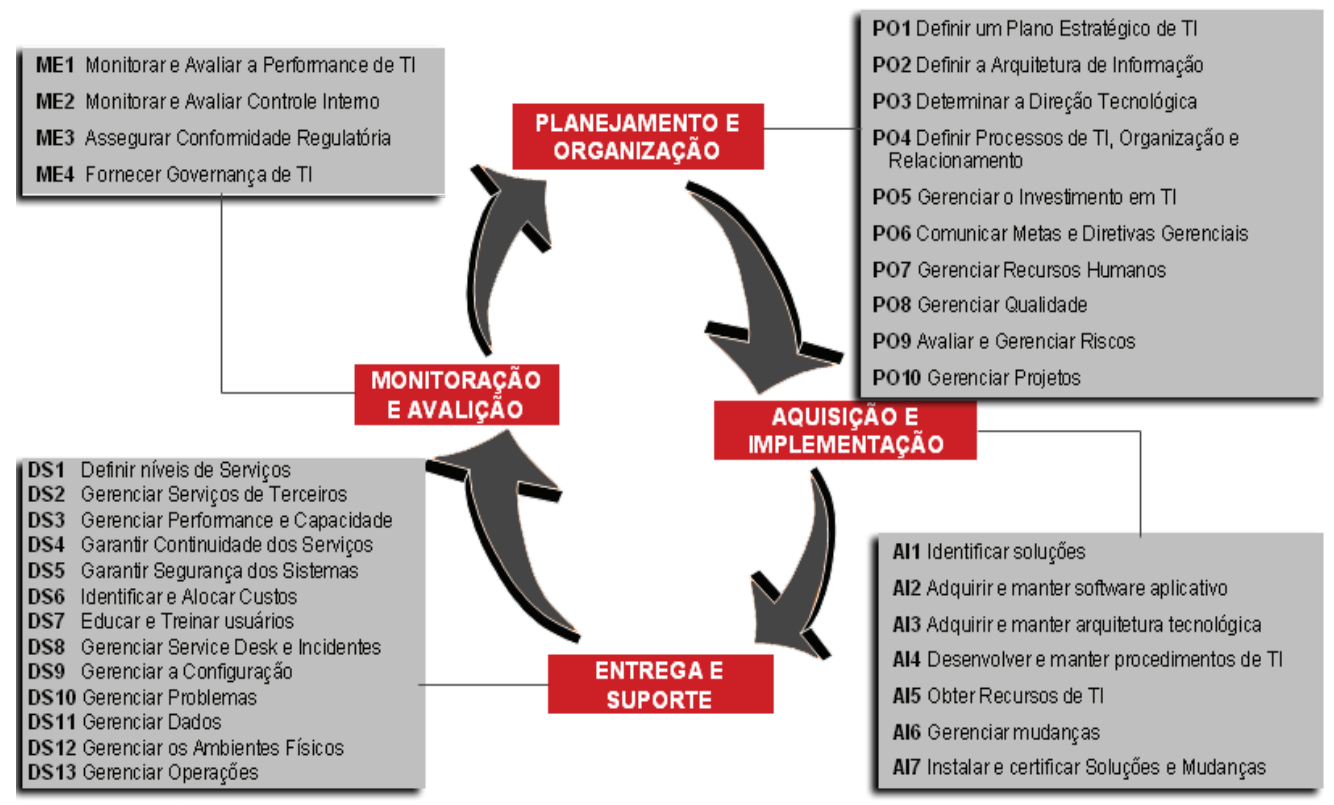

Figura 2: Grupos e Processos de Gestão.

Fonte: Adaptado de ISACA, 2015. 
Por meio desse gerenciamento dos processos, o CobiT também trata as informações por critérios de informação que têm como foco atender aos objetivos de negócios, ou seja, as informações precisam se adequar a certos critérios de controles, aos quais o CobiT denomina necessidades de informação da empresa.

Esses critérios são ancorados em requisitos de qualidade, guarda e segurança, sendo, portanto, sete critérios de informação distintos e sobrepostos que são definidos, como segue (ISACA, 2010):

i) Efetividade: lida com a informação relevante e pertinente para o desenvolvimento do processo em relação ao negócio, bem como, a mesma entregue em tempo, de maneira correta, consistente e utilizável.

ii) Eficiência: relaciona-se com a entrega da informação por meio do melhor (mais produtivo e econômico) uso dos recursos.

iii) Confidencialidade: está relacionada com a proteção de informações confidenciais para evitar a divulgação indevida.

iv) Integridade: relaciona-se com a fidedignidade e totalidade da informação bem como sua validade de acordo com os valores de negócios e expectativas.

v) Disponibilidade: relaciona-se com a disponibilidade da informação quando exigida pelo processo de negócio hoje e no futuro. Também está ligada à salvaguarda dos recursos necessários e capacidades associadas.

vi) Conformidade: lida com a aderência a leis, regulamentos e obrigações contratuais aos quais os processos de negócios estão sujeitos, isto é, critérios de negócios impostos externamente e políticas internas.

vii) Confiabilidade: relaciona-se com a entrega da informação apropriada para os executivos para administrar a entidade e exercer suas responsabilidades fiduciárias e de governança.

O CobiT dispõe também de um Modelo de Maturidade que serve para o gerenciamento e controle dos processos de TI e é ancorado num método de avaliar a organização, permitindo que ela seja pontuada de um nível de maturidade não-existente (0) a otimizado (5).

Essas práticas junto ao modelo de maturidade irão auxiliar o aperfeiçoamento dos processos da IC, assegurando a entrega dos serviços provendo métricas para julgar quando as coisas saem erradas.

\section{MÉTOdO DE PESQUISA}

Para a elaboração do método MAIC_CobiT, realizou-se inicialmente uma análise bibliométrica (1990 a 2014), como embasamento para o desenvolvimento do método de avaliação do ambiente de IC aliado ao CobiT. O MAIC_CobiT foi avaliado por especialistas da área com a finalidade de contribuir com uma análise mais eficiente por meio da experiência dos mesmos. Não houve a aplicação do método em uma empresa de pequeno ou médio porte com a finalidade de validar a funcionalidade do mesmo.

Então, para gerar o MAIC-Cobi'T, passou-se pela etapa de revisão bibliográfica identificando-se os ciclos de inteligência competitiva existentes, dos quais foi selecionado um deles, 
entre os 22 localizados, que serviu de base para a elaboração da proposta do método (selecionado o de Gomes; Braga, 2004), bem como, alguns aspectos pré-selecionados da norma CobiT v4.1 e, posteriormente, foi feita uma etapa de verificação de sua aplicabilidade por meio de um questionário junto a dez profissionais e acadêmicos, previamente selecionados.

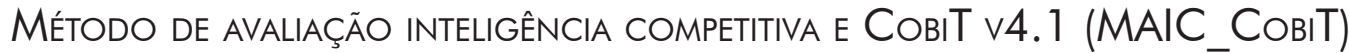

Por meio da revisão bibliográfica, verificou-se que muito foi explorado referente à IC, porém não houve utilização de boas práticas em qualquer situação. A finalidade de seu uso é poder auxiliar as empresas durante o desenvolvimento dos processos. Pela lacuna identificada, decidiu-se propor um método de avaliação que estivesse alinhado com normas de governança de TI (CobiT v4.1), em um ambiente de IC, verificando-se todos os processos de desenvolvimento da IC, de modo a auxiliar a gestão da área.

Então, o método proposto será chamado de MAIC_CobiT (Método de Avaliação Inteligência Competitiva e CobiT v4.1), e é diferente dos encontrados na literatura, que são descritos por ciclos, e em nenhum desses estudos se apresentou uma forma de avaliação que contemplasse boas práticas.

A estruturação geral do MAIC_CobiT está destacada no Quadro 5, contemplando os quatro grupos do CobiT, sendo que alguns processos desses grupos foram selecionados com base na aderência às experiências descritas por Gomes \& Braga (2004), que trazem consigo sua aplicação apresentando as dificuldades encontradas, além de ferramentas a serem utilizadas em cada etapa do ciclo de inteligência (cinco etapas). Em síntese, o MAIC_CobiT, exibe uma proposta de alinhamento entre CobiT e o Ciclo de Gomes \& Braga (2004), resultando na utilização de três grandes áreas, descritas posteriormente em detalhes.

Por meio desse alinhamento, identificaram-se quais seriam os processos do CobiT que deveriam ser avaliados no ambiente de IC, de tal forma que essa avaliação pudesse servir como um norteador para as empresas. Assim, foram relacionados os processos do CobiT com as etapas do ciclo de inteligência escolhido. Identificou-se também a possibilidade de desenvolvimento de um plano de ações por intermédio das recomendações do CobiT durante o desenvolvimento de seus processos.

Assim, devido a esses fatores, propôs-se o presente método, que tem por finalidade servir como referência para o desenvolvimento do ambiente de IC das empresas por meio de suas avaliações e planos de ações. 


\begin{tabular}{|c|c|c|}
\hline COBIT V4.1 & $\begin{array}{l}\text { MODELO GOMES \& BRAGA } \\
(2004)\end{array}$ & $\begin{array}{l}\text { PROPOSTA DE } \\
\text { ALINHAMENTO } \\
\text { COBIT v4.1 x IC }\end{array}$ \\
\hline $\begin{array}{l}\text { GRUPO: PLANEJAR E OR- } \\
\text { GANIZAR }\end{array}$ & \multirow{8}{*}{$\begin{array}{l}\text { 1. IDENTIFICAÇÃO } \\
\text { DAS NECESSIDÃES } \\
\text { DE INFORMAÇÃO }\end{array}$} & \multirow{8}{*}{$\begin{array}{l}\text { PLANEJAMENTO } \\
\text { E ORGANIZAÇÃO }\end{array}$} \\
\hline $\begin{array}{l}\text { PO1 Definir um Plano Estratégi- } \\
\text { co de TI }\end{array}$ & & \\
\hline $\begin{array}{l}\text { P02 Definir a Arquitetura da In- } \\
\text { formação }\end{array}$ & & \\
\hline $\begin{array}{l}\text { PO7 Gerenciar os Recursos Hu- } \\
\text { manos de TI }\end{array}$ & & \\
\hline $\begin{array}{l}\text { PO9 Avaliar e Gerenciar os } \\
\text { Riscos de TI }\end{array}$ & & \\
\hline $\begin{array}{l}\text { GRUPO: ADQUIRIR E IM- } \\
\text { PLEMENTAR }\end{array}$ & & \\
\hline $\begin{array}{l}\text { AI } 1 \text { Identificar Soluções Auto- } \\
\text { matizadas }\end{array}$ & & \\
\hline AI6 Gerenciar Mudanças & & \\
\hline $\begin{array}{l}\text { GRUPO: ENTREGAR E SU- } \\
\text { PORTAR }\end{array}$ & \multirow[t]{4}{*}{$\begin{array}{l}\text { 3. ANÁLISE DAS } \\
\text { INFORMAÇÕES }\end{array}$} & \multirow[t]{4}{*}{ CICLO DOS DADOS } \\
\hline $\begin{array}{l}\text { DS8 Gerenciar a Central de Ser- } \\
\text { viço e os Incidentes }\end{array}$ & & \\
\hline DS11 Gerenciar os Dados & & \\
\hline DS13 Gerenciar as Operações & & \\
\hline $\begin{array}{l}\text { GRUPO: MONITORAR E } \\
\text { AVALIAR }\end{array}$ & \multirow{5}{*}{ 5. AVALIAÇÃO } & \multirow{5}{*}{$\begin{array}{l}\text { MONITORAMENTO } \\
\text { E AVALIAÇÃO }\end{array}$} \\
\hline ME1 Monitorar e Avaliar o & & \\
\hline Desempenho & & \\
\hline $\begin{array}{l}\text { ME3 Assegurar a Conformidade } \\
\text { com Requisitos Externos }\end{array}$ & & \\
\hline ME4 Prover Governança de TI & & \\
\hline
\end{tabular}

Quadro 3: Relação entre os Processos do CobiT e as Etapas do Modelo de IC.

Fonte: Elaborado pelos autores.

Conforme o Quadro 3, dos processos que farão parte do MAIC_CobiT foram selecionados 12 entre os 34 processos do CobiT v4.1, sendo que o critério para a escolha desses 12 processos está no alinhamento entre o CobiT e o ciclo de IC. Outro fato que levou à escolha desses processos é que, conforme especifica o CobiT, nem sempre é necessário a utilização de todos os processos para se atingir o resultado esperado. Assim, optou-se por utilizar os 12 processos necessários para a avaliação da área de IC. 
Esses processos escolhidos foram identificados como processos chave para o desenvolvimento da IC, a partir da análise do Ciclo de Inteligência de Gomes \& Braga (2004).

O método proposto MAIC_CobiT será dividido em três grandes áreas: Planejamento e Organização; Ciclo dos Dados e Avaliação e Monitoramento.

Conforme analisado na literatura, houve um consenso entre os autores quanto à avaliação e ao planejamento. Assim, definiram-se as duas grandes áreas Planejamento e Organização e Avaliação e Monitoramento. Em seguida, propôs-se também a área de avaliação do Ciclo dos Dados. Essa área foi definida para avaliar os processos que compõem o fluxo de tratamento dos dados desde a coleta até a disseminação, facilitando a avaliação por meio de uma única grande área.

Portanto, as três grandes áreas foram definidas primeiramente com base na literatura. Em seguida, foram alinhadas ao Ciclo de Inteligência de Gomes \& Braga (2004), com a finalidade de facilitar o entendimento do funcionamento do método quanto às avaliações que seriam realizadas.

Essas três grandes áreas servirão de referência aos processos, ou seja, se a avaliação do planejamento for baixa significa que o restante do processo pode ter falhas, e assim por diante, ficando a critério da empresa acatar ou não o relatório gerado pela avaliação.

Das três grandes áreas definidas, duas podem ser consideradas base para o desenvolvimento do ciclo de IC, "Planejamento e a Avaliação". Conforme já destacado, essas duas áreas foram consenso entre os pesquisadores, entendendo-as como fundamentais.

Portanto, serão adaptados do CobiT, o processo: Planejamento e Organização, afinal sem planejamento sobre os seus processos é impossível desenvolver competitividade ou inteligência. Quanto à organização, define as atribuições e responsabilidades dentro do processo. A outra grande área é a Monitoramento e Avaliação, sendo apresentada também na maioria dos estudos (Quadro 1), que deve ser compreendida como controle de todo o processo, responsável pela avaliação de cada etapa individualmente e do ciclo como um todo, tendo por meta propor melhoria por meio de lições aprendidas dos resultados anteriores. A grande área Ciclo dos Dados se refere aos processos de coleta, análise e disseminação e deve ser compreendida como um ciclo contínuo, uma vez que, diariamente, são geradas inúmeras informações, assim sendo um novo foco ou direção para busca de informações pode ser designado, conforme o planejamento e a avaliação.

Para avaliação da Grande Área Planejamento e Organização são utilizados quatro entre dez processos propostos pelo CobiT.

Do CobiT o Grupo Planejar e Organizar os quatro processos a serem avaliados são:

i) PO1: Definir um plano estratégico de TI;

ii) PO2: Definir a arquitetura da Informação;

iii) PO7: Gerenciar os Recursos Humanos de TI;

iv) PO9: Avaliar e Gerenciar os Riscos de TI. 
Para avaliação da Grande Área Ciclo dos Dados são utilizados os seguintes processos:

i) Do CobiT o Grupo Adquirir e Implementar (AI) foram escolhidos dois entre sete processos, portanto, serão avaliados: AI1: Identificar Soluções Automatizadas e o AI6: Gerenciar Mudanças;

ii) Do CobiT o Grupo Entregar e Suportar (DS) foram escolhidos três entre 13 processos, portanto, serão avaliados: DS8: Gerenciar a Central de Serviço e os Incidentes; DS11: Gerenciar os Dados e DS13: Gerenciar as Operações.

Para avaliação da Grande Área, Avaliação e Monitoramento, foram utilizados três entre quatro processos do CobiT - Grupo Monitoramento e Avaliação:

i) ME1 - Monitorar e Avaliar o Desempenho;

ii) ME3 - Assegurar a Conformidade com Requisitos Externos;

iii) ME4 - Prover Governança de TI.

Para realizar a avaliação desses processos, foi utilizada a escala de maturidade do CobiT, na qual cada área deverá ser avaliada de 0 a 5 . O valor dessa escala serve como uma referência às situações propostas em cada uma das avaliações. Essas situações devem ser respondidas conforme o entendimento do responsável de acordo com a situação atual da área.

A escala proposta pelo CobiT, com valores entre 0 e 5 , tem as seguintes atribuições:

0) Inexistente: A empresa não reconhece a necessidade do processo e não existe consciência sobre a importância do mesmo.

1) Intuitivo: A empresa tem consciência sobre a importância do processo, porém o processo é inexistente.

2) Inicial: A empresa tem consciência sobre a importância do processo e começa a definir parâmetros para a execução dos mesmos.

3) Definido: Todo o processo é documentado e existe um método que auxilia todo o processo.

4) Gerenciável: Foram definidos indicadores de desempenho que auxiliam o gerenciamento dos processos por meio da análise dos mesmos.

5) Otimizado (Proativo): Todo processo é dinâmico, os envolvidos são participativos e todos têm direito a contribuir com o mesmo durante as reuniões ou nas ações do dia a dia.

Por meio das avaliações dos processos realizados anteriormente, identificou-se a possibilidade de propor um plano de ação para cada Grande Área.

Tal proposta, por área, está fundamentada no CobiT, via suas diretrizes e recomendações com as recomendações de Gomes; Braga (2004) em seu estudo. Assim, com essa integração, foi possível criar um plano de ações demonstrando em cada situação O QUE poderia ser feito para realizar melhorias no ambiente de IC.

A partir desse relacionamento entre CobiT e IC, iniciou-se o desenvolvimento do método de avaliação composto por três etapas e seis subetapas (Figura 3), sendo:

ETAPA 1: avaliação por grande área

- $\quad$ etapa 1.1: avaliação do grupo Planejamento e Organização; 
- $\quad$ etapa 1.2: avaliação do Ciclo dos Dados;

- $\quad$ etapa 1.3: avaliação do grupo monitoramento e avaliação

ETAPA 2: análise consolidada das grandes áreas

- Após o preenchimento das três avaliações da Etapa 1, é realizada a análise dos resultados;

ETAPA 3: plano de ação por grande área

- Após a análise, é demonstrado quais são os passos a serem seguidos composto por três planos de ações (Etapas 3.1, 3.2, 3.3), que podem auxiliar a empresa a melhorar seu ambiente de IC.

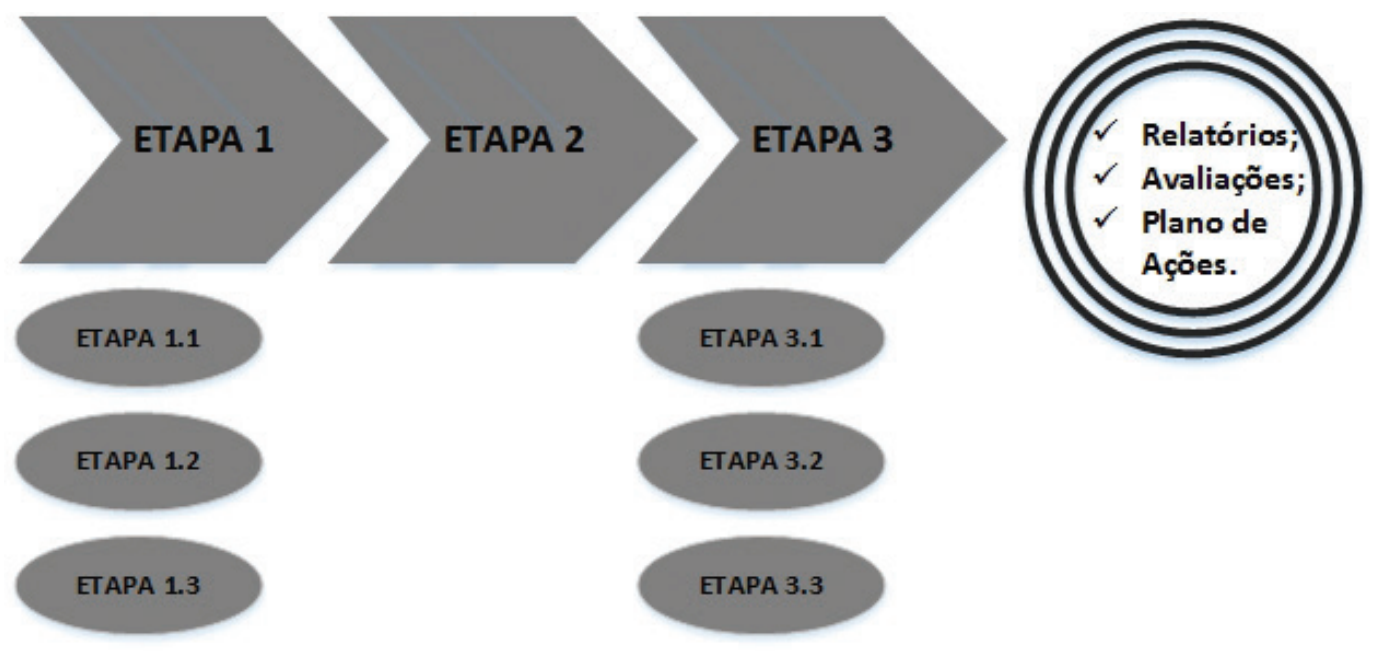

Figura 3: Etapas e subetapas do método MAIC_CobiT.

Fonte: Elaborada pelos autores.

\section{IMPLANTAÇÃO DO MÉTODO MAIC_COBIT VIA PLANILHA ELETRÔNICA}

Com a finalidade de facilitar o uso do método MAIC_CobiT, decidiu-se propor uma implantação via planilha eletrônica (MS-Excel $\left.{ }^{\circledR}\right)$, de modo a torná-lo acessível tanto a acadêmicos quanto a profissionais.

Também, a partir dessa implantação via planilha eletrônica, buscou-se verificar, com alguns acadêmicos e profissionais, suas opiniões e pontos de vistas referentes ao uso do método de avaliação.

Inicialmente, é apresentada uma tela com o esquema de funcionamento do Método, conforme Figura 4, destacando-se as três etapas e as seis subetapas, de acordo com o já descrito. O método faz três avaliações iniciais das grandes áreas (Etapas 1.1; 1.2 e 1.3), seguindo para a avaliação consolidada das grandes áreas (Etapa 2) e, finalmente, gera o Plano de Ação por Grande Área (Etapa 3). 


\begin{tabular}{|c|c|c|c|c|}
\hline ETAPA 1 & ETAPA 2 & ETAPA 3 \\
\hline AVALIAÇÃO DAS GRANDES ÁREAS & $\begin{array}{c}\text { AVALIAÇÃO CONSOLIDADA DAS } \\
\text { GRANDES ÁREAS }\end{array}$ & $\begin{array}{c}\text { PLANO DE AÇÕES PARA AS GRANDES } \\
\text { ÁREAS }\end{array}$ \\
\hline & & & & \\
\hline & & & & \\
\hline
\end{tabular}

Figura 4: Etapas do Método MAIC-CobiT.

Fonte: Elaborado pelos autores.

Após essa visão geral das etapas, o usuário será direcionado ao tutorial da ferramenta proposta (Figura 5), nessa tela são detalhados todos os botões e funcionalidades.

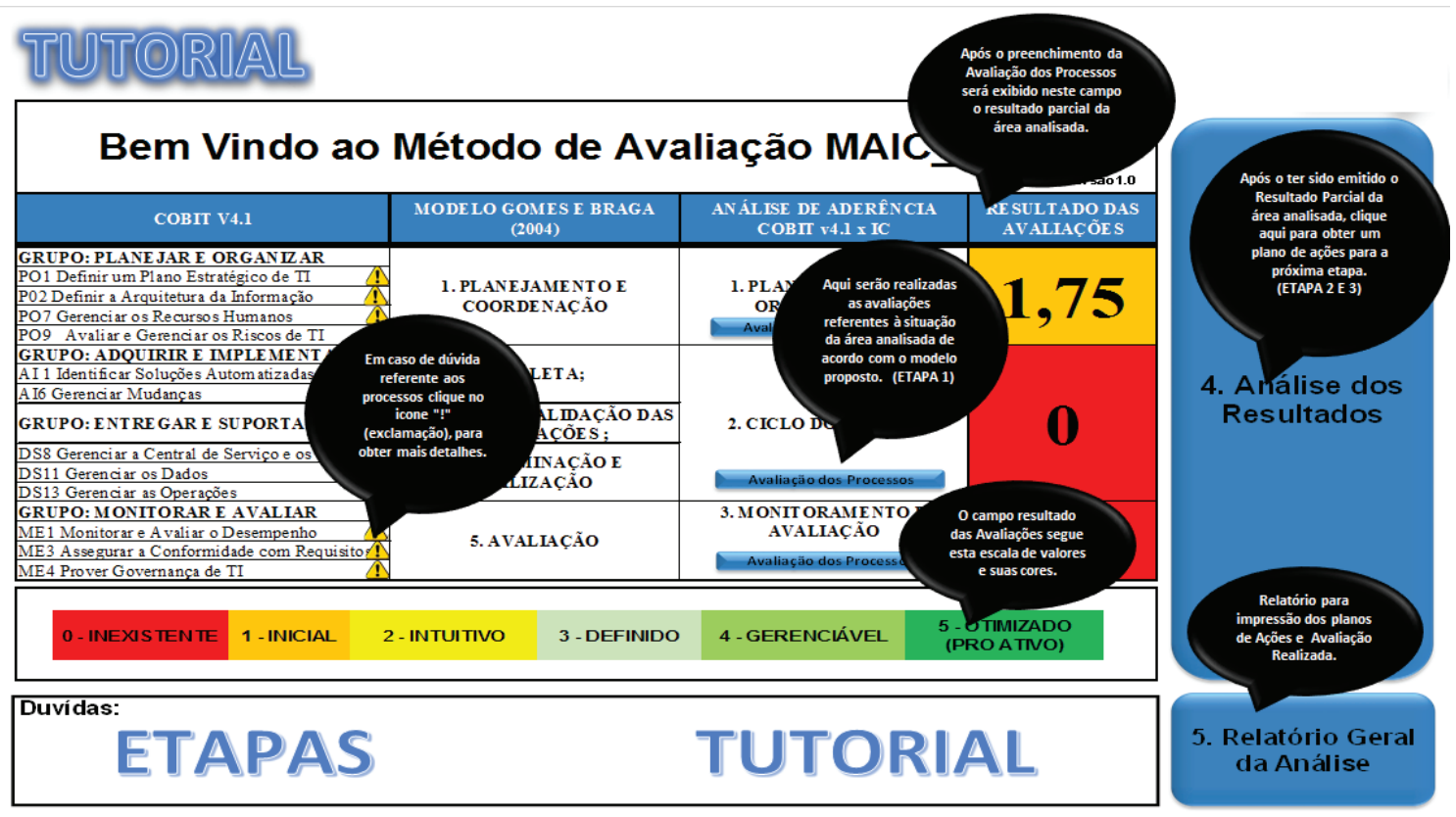

Figura 5: Tutorial do Método MAIC_CobiT.

Fonte: Elaborada pelos autores.

Após a compreensão das funções das ferramentas, o usuário é direcionado para a Tela Inicial (Figura 6), na qual pode realizar as avaliações do ambiente de IC. 

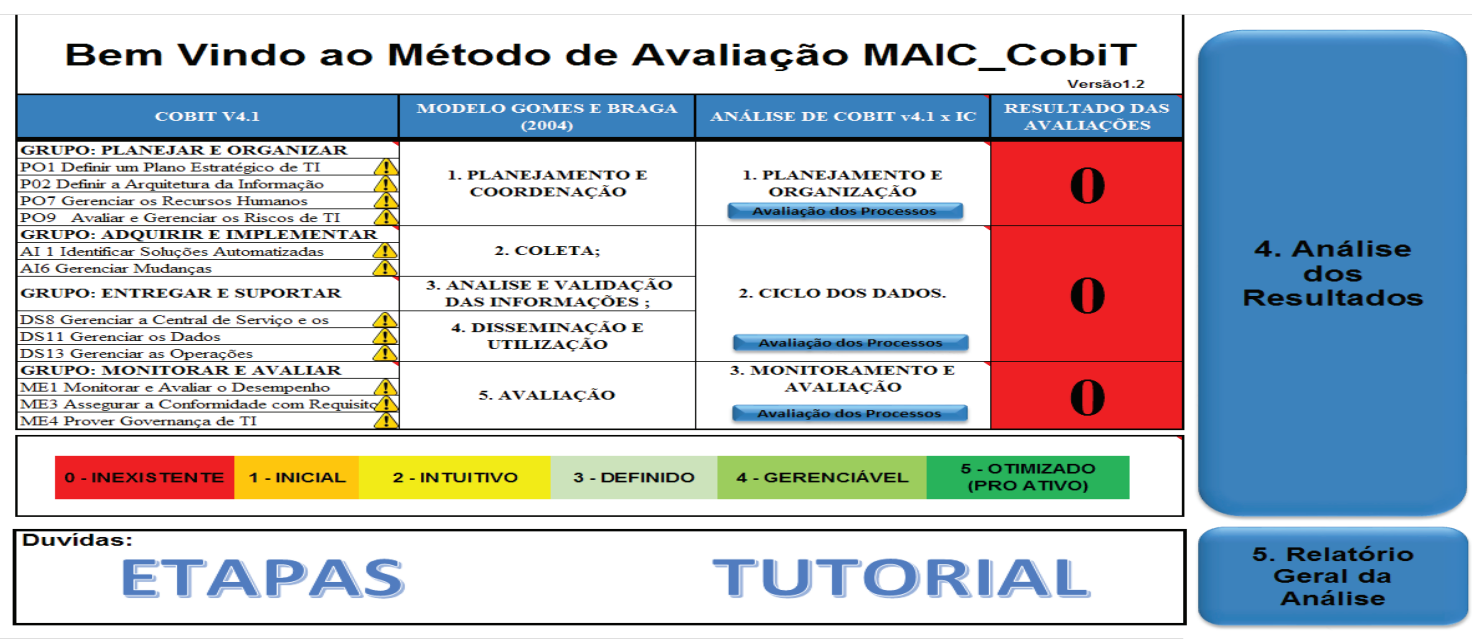

Figura 6: Tela Inicial do método MAIC_CobiT.

Fonte: Elaborada pelos autores.

Pressionando-se o botão "avaliação dos processos" o usuário é direcionado para a tela de avaliação das grandes áreas, conforme área que for selecionada. Após a finalização do preenchimento das avaliações (questões com múltipla escolha em seis níveis de 0 a 5, sendo zero inexistente), serão apresentados os resultados preliminares na avaliação na tela inicial (Figura 7), seguindo a escala de cores como referência aos resultados das avaliações.

\section{Bem Vindo ao Método de Avaliação MAIC_CobiT}

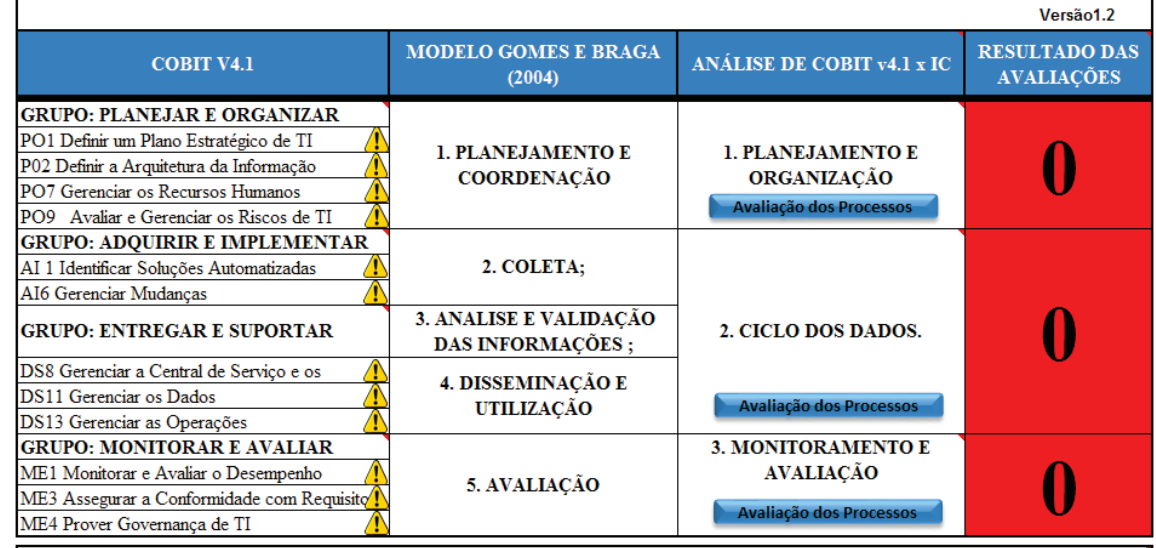

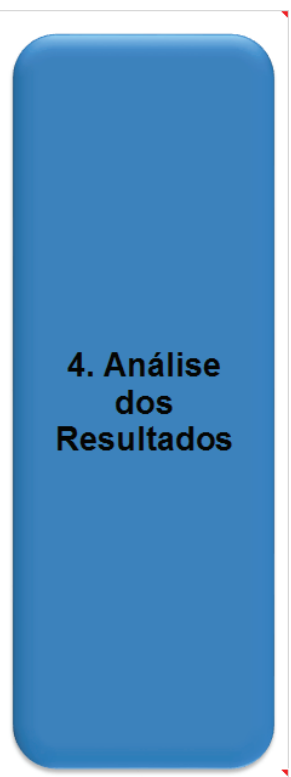

Duvídas:

\section{ETAPAS}

5. Relatório

Geral da

Análise

Figura 7: Resultado Preliminar das Avaliações.

Fonte: Elaborada pelos autores. 
Após a finalização das avaliações, o usuário deve seguir para a Análise dos Resultados, na qual são apresentados os resultados da Etapa 2.

A apresentação ocorre por meio de um dashboard (Figura 8), cujos relógios servem como indicadores da atual situação da área, e é com base neles que são emitidas algumas recomendações e sugestões.

Logo abaixo dos relógios estão as informações referentes à avaliação consolidada das grandes áreas, em que é apresentada a situação atual com base nos quatro princípios da governança.

E, por fim, estão as definições dos termos apresentados na avaliação consolidada das grandes áreas.

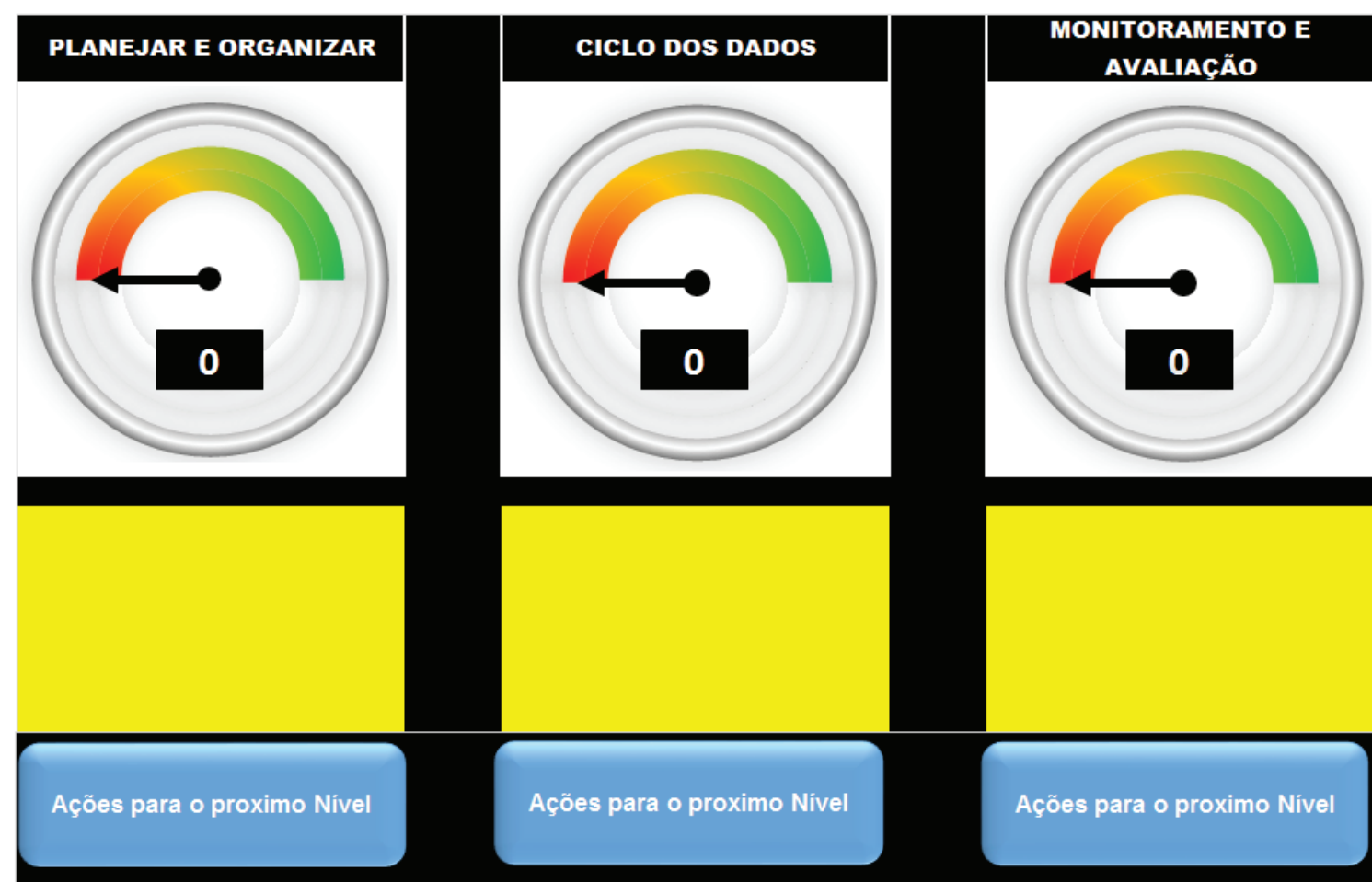

Responsabilidade - Com a marca da empresa, com os produtos ou serviços que entrega, com o investimento realizado, com a sociedade e com seus profissionais.

Transparência - Toda a informação a respeito dos processos de negócio deve ser transparente para os acionistas e para a sociedade. O modelo utilizado deve ser auditável com base em padrões conhecidos que demonstrem claramente a veracidade dos dados.

Imparcialidade - A informação não deve ser tratada de maneira tendenciosa ou favorável a um grupo ou a uma situação especifica. Os objetivos do negócio e a visão da empresa, assim como suas políticas, inclusive a de segurança, devem nortear o uso da informação de maneira imparcial.

Comunicação - Toda informação deve ser divulgada a todos que forem de direito. O balanço, os objetivos, as propostas realizadas, as planejadas e não realizadas e os planos de ação devem estar disponiveis em meios de fácil acesso e em linguagem objetiva, evitando a todo custo termos técnicos que não sejam pertinentes à interpretação dos resultados.

Figura 8: Dashboard - Resultados Consolidados das Áreas.

Fonte: Elaborada pelos autores. 
Após a apresentação dos resultados consolidados (Figura 8), o usuário tem a opção de escolher qual plano de ação que deverá ser seguido.

A escolha deve ser feita conforme a área avaliada, ou na sequência proposta pela pesquisa (Planejamento, Ciclo dos Dados e Avaliação).

Ao selecionar a opção desejada, é apresentada a situação Atual e Futura, caso haja interesse do usuário os resultados podem ser impressos (Figura 9).

Ainda na página inicial existe um botão para realização da impressão das avaliações, por meio deste é possível imprimir relatório de todas as áreas ou somente da área avaliada.

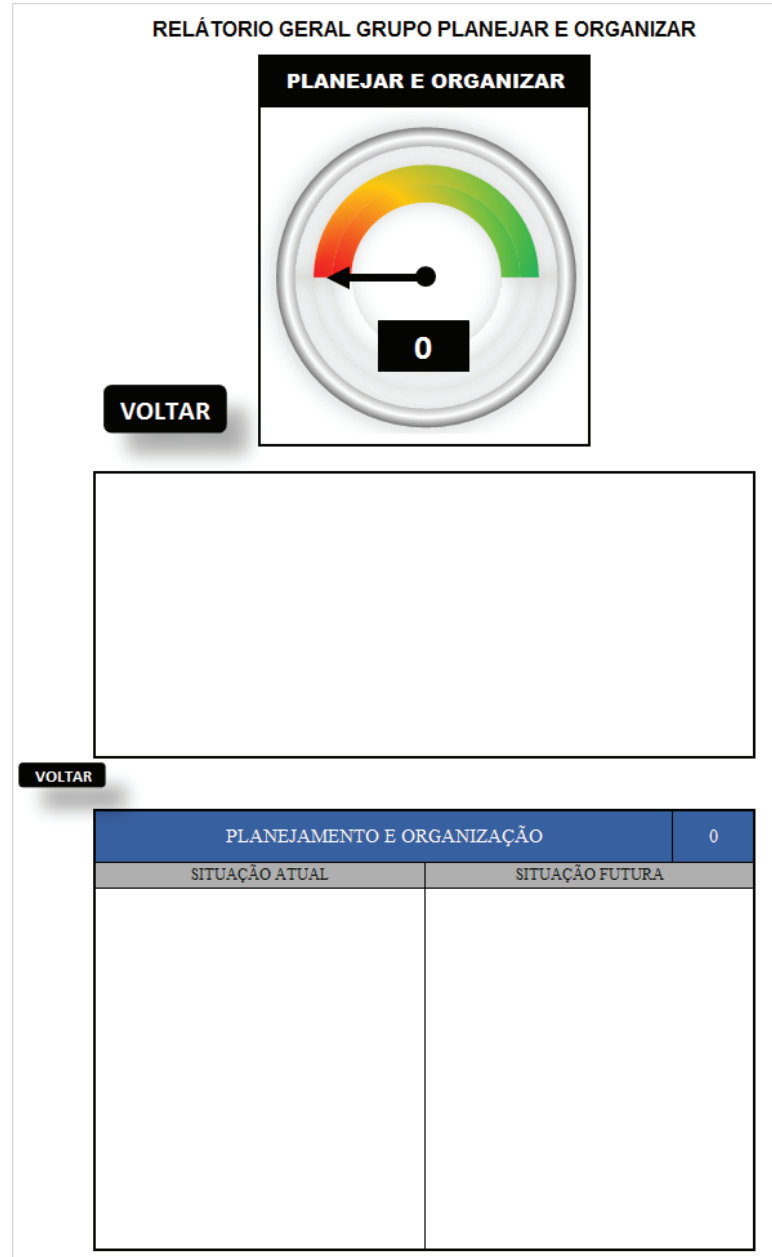

Figura 9: Tela Relatório dos planos de ações do método.

Fonte: Elaborada pelos autores. 


\section{ANÁLISE DA APLICAÇÃO DO MÉTODO MAIC_COBIT}

Foi feita uma iniciativa de se verificar a relevância e aplicação do método junto a 7 (sete) especialistas/profissionais e 8 (oito) acadêmicos, que trabalham e/ou pesquisam sobre Governança de TI e IC, logo com ligações diretas à temática da pesquisa com a intenção de se averiguar, principalmente, as possibilidades da aplicação prática desse Método.

É preciso destacar que essa amostra foi totalmente intencional e não teve a pretensão de rigor estatístico algum, foi exclusivamente para colher impressões e opiniões quanto à estrutura do método e sua aplicabilidade. Esses grupos foram selecionados e contatados a partir de algum relacionamento anterior, seja profissional ou acadêmico.

Então, a finalidade desta análise foi fundamental para verificação dos principais elementos do Método bem como de sua aplicabilidade, tanto do ponto de vista acadêmico como do ponto de vista profissional.

Assim, esses dois grupos de respondentes foram contatados via e-mail no qual uma carta de apresentação da pesquisa foi enviada e um link http://goo.gl/forms/ZKLIM4imtR para acesso ao questionário de avaliação foi passado com os principais aspectos do Método MAIC_ COBiT, bem como, com a planilha eletrônica do Método implementado. A única finalidade foi a de verificar a aplicabilidade do Método, portanto o questionário não utilizou rigor metodológico, mas foi montado com certa estruturação lógica, composto por 10 questões, sendo nove delas com múltipla escolha (escala Likert de 1 a 5, adaptada para cada assunto envolvido na questão) e uma última questão totalmente aberta para que se colocasse as impressões do Método (Apêndice A). Esse questionário foi desenvolvido em formulário no Google Forms e um link ficou disponível para o respondente acessá-lo.

A partir dessa verificação feita por meio desse questionário digital, após o retorno dos 15 (quinze) respondentes, ficou demonstrada sua viabilidade de uso e relevância, tanto pela ótica acadêmica como empresarial, além disso, demonstrou-se que a forma que o Método foi exibido foi bem aceita pela maioria dos usuários.

O método apresenta também uma avaliação próxima à real situação da empresa servindo como um norteador, conforme destacado por esses respondentes durante o processo de verificação. Quanto a isso se destaca que 82,5\% (cerca de 13 deles) responderam como aplicável na realidade de trabalho, ou seja, contribui e é relevante para a realidade das empresas que decidirem adotar esse Método MAIC_CoBiT.

Ainda, via questionário, verificou-se que existe uma deficiência quanto às empresas que utilizam ambos os temas (Norma CobiT e Aspectos de IC), demonstrando uma necessidade das empresas estarem atentas ao que acontece ao seu redor, e não se preocupar somente com sua situação interna, pois os fatores externos impactam diretamente nos negócios da empresa.

\section{CONSIDERAÇÕES FINAIS}

Conforme observado na literatura, as atividades internas de IC são fundamentais para as empresas se manterem competitivas. O Brasil está iniciando um processo de maturidade em 
relação à IC, pois é uma ferramenta utilizada de forma reativa e sem padronização. De acordo com o analisado na literatura, não existe um tamanho mínimo de empresa para usar a IC ou CobiT, e mesmo assim ainda são práticas pouco utilizadas por empresas brasileiras.

Existem diversos ciclos de IC (22 ciclos) que têm a finalidade de auxiliar as empresas, porém eles possuem muitas semelhanças e particularidades, mas nenhum desses ciclos está vinculado a uma norma, e até então não havia uma forma sistematizada de diagnosticar os ambientes de IC.

Por sua vez, existe também a norma internacional de governança de TI (CobiT v4.1) que tem muita aderência com os ciclos de IC identificados. Por meio desta pesquisa, identificou-se que é possível a utilização dessa norma junto a um ciclo de IC, sistematizando o processo e criando um método de diagnóstico da área.

Portanto, o objetivo deste trabalho foi de apresentar um método de avaliação do ambiente de IC com base na norma internacional de governança de TI (CobiT v4.1) com a finalidade de diagnosticar as possíveis ineficiências da área e propor melhorias no sistema de IC. Esse objetivo foi atingido e gerou o método aqui denominado de MAIC_CoBiT.

Esse método MAIC_CoBiT contribui para o desenvolvimento das atividades relacionadas à IC nas empresas, permitindo um diagnóstico regular e contínuo das possíveis melhorias do ciclo de IC e listando recomendações por meio do plano de ações, caso a caso, como soluções para otimizar suas etapas. A partir da análise dessas recomendações, a empresa poderá decidir pela sua implementação ou não. O método apresenta três avaliações referentes às grandes áreas definidas. Após as avaliações, exibe uma avaliação consolidada e, em seguida, permite que sejam consultados os três planos de ações gerados, de acordo com as grandes áreas avaliadas. Portanto, o método avalia o ambiente, mostra um resultado e um plano de ações, desse modo auxiliando as empresas a sempre buscar uma melhoria de seu ambiente.

Conforme já destacado, a presente pesquisa atingiu seu objetivo, pois o método foi bem aceito e poucas alterações foram descritas e/ou sugeridas. Após o retorno dos questionários pelos respondentes (profissionais e acadêmicos), não foram realizadas alterações significativas no método.

O método gerado neste trabalho - MAIC_CoBiT - é uma referência inicial para o desenvolvimento de novas ferramentas de melhoria dos processos relacionados à IC.

Assim, como toda pesquisa, esta pesquisa também tem suas limitações. A primeira limitação é o fato de o método não apresentar o "COMO FAZER" referente às ineficiências detectadas, sendo que ele apresenta "O QUE FAZER", afinal existe muitas particularidades entre uma empresa e outra.

A segunda limitação está em não considerar sistematicamente o grau de maturidade do CoBiT que a empresa possui em seus processos de TI, o que seria de grande importância para garantir um melhor desenvolvimento da área de IC por meio do método proposto (MAIC_CobiT).

Espera-se que essas limitações sejam superadas na medida em que novas pesquisas forem desenvolvidas acerca do tema, ou ainda, por meio da aplicação desse método identificando-se possíveis novas melhorias ou até mesmo uma nova metodologia de avaliação da área de IC. 
Por fim, é preciso destacar algumas contribuições advindas do método sob dois pontos de vista:

Do ponto de vista empresarial, o método serve como um norteador para "O QUE FAZER" no ambiente de IC, por meio das avaliações e planos de ações, caso a caso, de acordo com as grandes áreas propostas. Além disso, oferece uma diretriz que favorece o monitoramento do ambiente a partir do que está definido em uma norma internacional mundialmente reconhecida que é o CoBiT.

Do ponto de visto acadêmico, o trabalho contribui com a integração entre IC dentro do contexto de Governança de TI, a partir do mapeamento e identificação dos ciclos de inteligência existentes verificando-se seus pontos em comum e da possibilidade de se utilizar e explorar em detalhes os processos identificados em uma norma de boas práticas de governança que é o CoBiT. Isso viabiliza o conhecimento relacionado com alinhamento estratégico entre TI e operações, por exemplo. A outra contribuição acadêmica está na identificação da lacuna que foi utilizada na pesquisa, e na exploração desse assunto que, para o Brasil, ainda é um tema emergente, dando indícios para outras carências e necessidades para trabalhos futuros serem desenvolvidos.

\section{Agradecimento}

À CAPES (Coordenação de Aperfeiçoamento de Pessoal de Nível Superior) pelo apoio a esta pesquisa via Bolsa de Estudos do Programa CAPES/PROSUP.

\section{RefERÊNCIAS}

ABRAIC. Código de Ética. Disponível em: http://www.abraic.org.br/v2/conteudo.asp?c=3 acessado em: 04/02/2015.

ALCARÁ, A. R. et al. As redes sociais como instrumento estratégico para a inteligência Competitiva. TransInformação, Campinas, v. 18, n. 2, p. 143-153, mai./ago. 2006.

ALI, S. GREEN, P. ROBB, A. Information technology investment governance: What is it and does it matter? International Journal of Accounting Information Systems, v. 18, p. 1-25, 2015.

AMARAL, R. M.; GARCIA, L. G.; FARIA, L. I. L.; ALIPRANDINI, D. H. Modelo para o Mapeamento de Competências em Equipes de Inteligência Competitiva. Ciência da Informação, v. 37, n. 2, 2008.

ANDRADE, A., \& ROSSETTI, J. P. Governança corporativa: fundamentos, desenvolvimento e tendências. S. Paulo: Atlas, 2004.

ANJOS, L. A. M.; MOURA, H. P. Um Modelo para Avaliação de Produtos de Software. Disponível em: http://www.cin.ufpe.br/hermano/laps/download/laps-um-modelo-para-avaliacao-de-produtos-de-software.pdf $(27 / 08 / 2015)$.

BALLONI, A. J. Por que gesiti - Porque gestão em tecnologia da Informação? 1. ed. 
Komedi, 2015.

BRODERICK, J. S. ISMS, security standards and security regulations. Information Security Technical Report, v. 11, n. 1, p. 26-31, 2006.

CAMPOS, F. C. SANTOS, G. S. GOVERNANÇA NA OFERTA DE SERVIÇOS: Modelo de Outsourcing para Provedores de Tecnologia da Informação - MOPP. Editora Atlas, 1. ed. 2012.

CANONGIA, C. SANTOS, D. M. SANTOS, M. M. ZACKIEWICZ, M. Foresight, Inteligência Competitiva e Gestão do Conhecimento: Instrumentos para a Gestão da Inovação. Revista Gestão e Produção, v. 11, n. 2, p. 231-238, mai./ago. 2007.

CAPUANO, E. A. CASAES, J. COSTA, J. R. JESUS, M. S. \& MACHADO, M. A., Inteligência competitiva e suas conexões epistemológicas com gestão da informação e do conhecimento. Ci. Inf. Brasília, v. 38, n. 2, p. 19-34, 2009.

$\mathrm{CHOO}, \mathrm{C}$. W. Information management for the intelligent organization: the art of scanning the environment, 2. ed. 1998.

CobiT v4.1. Governança, Controles e Auditoria de TI. IT Governance Institute, 2010. Acessado em: 04/02/2015.

COZZARIN, B. P. AND PERCIVAL, J. C. "Complementarities between organizational strategies and innovation", Economics of Innovation and New Technology, v. 15, n. 3, p. $195 \square 217,2006$.

DISHMAN, P.; CALOF, J. L. The intelligence process: frontend to strategic planning, Editora Ottawa, 2002.

EXAME. Inteligência Competitiva nas empresas brasileiras. Disponível em: http://exame.abril.com.br/rede-de-blogs/brasil-no-mundo/2013/09/24/inteligencia-competitiva-nas-empresas-brasileiras, 2013.

FELMAN, M., GERTLER, M. AND WOLFE, D. "University technology transfer and national systems of innovation: introduction to the special issue of industry and innovation", Industry and Innovation, v. 13, n. 4, p. 359 70, 2006.

FLEISHER, J. P. AND LEE, C. V. "Information technology as a facilitator for enhancing dynamic capabilities through knowledge managements", Information \& Management, v. 41, n. 8, p. $933 \square 45,2004$.

FRANCO, M. MAGRINHO, A. Silva, J. R. "Competitive intelligence: a research model tested on Portuguese firms", Business Process Management Journal, v. 17, Iss: 2, p. 332-356, 2011.

GIL, A. C. Como elaborar projetos de pesquisa, 4. ed. São Paulo: Atlas, 2007.

GOMES, E. \& BRAGA, F. Como Transformar Informação em um Negócio Lucrativo, 2. ed. Rio de Janeiro: Elsevier, 2004. 
HARDY G. Using IT governance and COBIT to deliver value with it and respond to legal, regulatory and compliance challenges. Inf Secur Tech Rep, p. 55-61, 2006.

ISACA. CobiT. Disponível em: http://www.isaca.org/Knowledge-Center/COBIT/Pages/ Overview.aspx acessado em: 06/02/2015.

ITSMF (Service Management Forum) disponível em: http:/ /www.itsmf.com.br. Acessado em: 10.05.2015.

KAHANER, L. Competitive Intelligence: How to gather, analyze, and use information to move your business to the top. Nova York: Touchstone Books, 1996.

LUNARDI, G. L. BECKER, J. L. MAÇADA, A. C. G “\& DOLCI, P.C. The impact of adopting IT governance on financial performance: An empirical analysis among Brazilian firms. International Journal of Accounting Information Systems, v. 15, n. 1, p. 66-81, 2014.

MARNEWICKA, C. LABUSCHAGNEB, L. An investigation into the governance of information technology projects in South Africa. International Journal of Project Management, v. 29, Issue 6, p. 661-670, 2011.

MIGUEL, P. A. C. et al. Metodologia da Pesquisa Científica em Engenharia de Produção e Gestão de Operações, 2. ed. Rio de Janeiro: Elsevier (ABEPRO), 2012.

PASSOS, A. Inteligência Competitiva para pequenas e médias empresas. São Paulo: ,2007.

PELLISSIER, R. NENZHELELE, T. E. Towards a universal competitive intelligence process model. S.A Journal of Information Management, v. 15, n. 2, 2013.

PERCIVAL, J. C. AND COZZARIN, B. P. "Complementarities affecting the returns to innovation”, Industry and Innovation, v. 15, n. 4, p. 371 92, 2008.

PORTER, M. Vantagem Competitiva. Rio de Janeiro: Campus, 1996.

PRESCOTT, J. E. Inteligência competitiva - Lições das trincheiras. Rio de Janeiro: Editora Campus, 2002.

PRODANOV, C.; FREITAS, E. Metodologia do Trabalho Científico: Métodos e Técnicas da Pesquisa e do Trabalho Acadêmico, 2. ed. Novo Hamburgo: Universidade FEEVALE, 2013.

QUEYRAS, J., \& QUONIAM, L. Inteligência competitiva. Inteligência, informação e conhecimento. Brasília: IBICT; UNESCO, p. 73-97, 2006.

RIBEIRO, A. C. “TÉCNICAS DE CONTRA INTELIGÊNCIA: Falsa Informação, Desinformação e Decepção.” Revista Proteger, 2010.

RODRIGUES, L. C.; RISCAROLLI, V. ALMEIDA, M. I. R. Inteligência Competitiva No Brasil: Um Panorama Do Status E Função Organizacional. Revista Intel. Com. São Paulo, v. 1, n. 1, p. 63-85, abr./jun. 2011. 
RODRIGUEZ, M. V.; FONTANA, E. W. Inteligência competitiva: nível de uso e influência nas receitas nos pequenos negócios exportadores. Universidade Federal Fluminense, Niterói/ RJ, v. 11, n. 45, p. 1-26, mai./jun. 2005.

ROUACH, D. SANTI, P. Competitive Intelligence Adds Value: Five Intelligence Attitudes. European Management Journal, v. 19, n. 5, p. 552-559, 2001.

SCIP. Code of Ethics. Disponível em: http://www.scip.org/About/content.cfm?ItemNumb $\underline{\text { er}=578 \& \text { navItemNumber }=504}$ acessado em: 04/02/2015.

SEWDASS, N. \& DU TOIT, A. Current state of competitive intelligence in South Africa. International Journal of Information Management, v. 34, n. 2, p. 185-190, 2014.

STAREC, C. GOMES, E. e BEZERRA, J. “Gestão Estratégica da Informação e Inteligência Competitiva.” São Paulo: Editora Saraiva, 2006.

STRAUSS, A. C., \& DU TOIT, A. S. A. Competitive intelligence skills needed to enhance South Africa's competitiveness, Aslib Proceedings, v. 62, Iss: 3, p. 302-320, 2010.

SWARTZ, N. Competitive Intelligence underutilized. Information Management Journal, v. 39, n. 3, p. 10, 2005.

TEIXEIRA, R. C.; SOUZA, R. R. O uso das informações contidas em documentos de patentes nas práticas de Inteligência Competitiva: apresentação de um estudo das patentes da UFMG. Perspectiva em Ciência da Informação, v. 18, n. 1, p. 106-125, jan./mar. 2013.

TYSON, K. W. M. The complete guide to competitive intelligence. Chicago: Kirk Tyson International, 1998.

WEILL P, ROSS J. IT governance: how top performers manage it decisions rights for superior results. Watertown: Harvard Business School Press, 2004.

ZHENG, Z. FADER, P. PADMANABHAN, B. From Business Intelligence to Competitive Intelligence: Inferring Competitive Measures Using. Journal of Social Science Research Network, 2013.

Submetido em: 22-3-2018

Aceito em: 28-11-2018

"O presente trabalho foi realizado com apoio da Coordenação de Aperfeiçoamento de Pessoal de Nível Superior - Brasil (CAPES) - Código de Financiamento 001”.

"This study was financed in part by the Coordenação de Aperfeiçoamento de Pessoal de Nível Superior - Brasil (CAPES) - Finance Code 001”. 
APÊNDICE A: Questionário utilizado na pesquisa de verificação do MAIC_CoBiT

\begin{tabular}{|c|c|c|c|c|c|}
\hline Questão & 1 & 2 & 3 & 4 & 5 \\
\hline $\begin{array}{l}\text { TEMA INTELIGÊNCIA COMPETITIVA } \\
\text { QUAL CONHECIMENTO POSSUI SOBRE ESSE ASSUNTO? }\end{array}$ & & & & & \\
\hline $\begin{array}{l}\text { TEMA COBIT V4.1 } \\
\text { QUAL CONHECIMENTO POSSUI SOBRE ESSE ASSUNTO? }\end{array}$ & & & & & \\
\hline $\begin{array}{l}\text { CONTEÚDO DO MÉTODO } \\
\text { QUAL SUA OPINIÃO ESPECIFICAMENTE SOBRE OS ASSUN- } \\
\text { TOS E TEMAS ABORDADOS, REFERENTE A ESSA SOLUÇÃO } \\
\text { HÍBRIDA PROPOSTA PELO MAIC_CObiT? }\end{array}$ & & & & & \\
\hline $\begin{array}{l}\text { FORMA DE APRESENTAÇÃO DO MÉTODO } \\
\text { QUAL SUA OPINIÃO SOBRE A FORMA COMO O MÉTODO FOI } \\
\text { DESENVOLVIDO? }\end{array}$ & & & & & \\
\hline $\begin{array}{l}\text { QUANTO À ACURÁCIA } \\
\text { QUAL A PROXIMIDADE ENTRE O VALOR OBTIDO EXPERI- } \\
\text { MENTALMENTE E O VALOR VERDADEIRO NA MEDIÇÃO, OU } \\
\text { SEJA, O MÉTODO MAIC_CObiT TRADUZ COM PRECISÃO UMA } \\
\text { ANÁLISE REAL? }\end{array}$ & & & & & \\
\hline $\begin{array}{l}\text { APLICABILIDADE } \\
\text { A INFORMAÇÃO PASSADA TEM APLICABILIDADE NA SUA } \\
\text { PRÁTICA DIÁRIA DE TRABALHO, OU SEJA, HÁ POSSIBILIDA- } \\
\text { DE DAS ANÁLISES DO MÉTODO MAIC_CObiT FAVORECEREM } \\
\text { OS PROCESSOS DECISÓRIOS E/OU GERAREM PLANOS DE } \\
\text { AÇÕES? }\end{array}$ & & & & & \\
\hline $\begin{array}{l}\text { COM BASE NAS INFORMAÇÕES APRESENTADAS, VOCÊ SE } \\
\text { SENTE CAPAZ DE APLICAR OS CONHECIMENTOS EXPOSTOS } \\
\text { PELO MÉTODO MAIC_CobiT? }\end{array}$ & & & & & \\
\hline $\begin{array}{l}\text { APREENSIBILIDADE } \\
\text { É FÁCIL APRENDER A USAR O MÉTODO MAIC_CobiT? }\end{array}$ & & & & & \\
\hline $\begin{array}{l}\text { INTELIGIBILIDADE } \\
\text { QUANTO À COMPREENSÃO SOBRE OS CONCEITOS E A APLI- } \\
\text { CAÇÃO QUE O MÉTODO MAIC_CobiT APRESENTA? }\end{array}$ & & & & & \\
\hline
\end{tabular}

\section{Questão discursiva: PONTO DE VISTA DO AVALIADOR}

Por favor, faça críticas, sugestões e comentários sobre o método MAIC_CobiT. Sua avaliação é muito importante para que possamos aprimorar o método MAIC_CobiT. OBRIGADO POR TER CONTRIBUÍDO COM ESTA PESQUISA. 